\title{
Coordination-enhanced photochromism in dysprosium dinuclear complexes with photomodulated single-molecule magnet behavior
}

\author{
Lucie Norel,,$+^{*}$ Kevin Bernot, ${ }^{\dagger}{ }^{\wp}$ Frédéric Gendron, ${ }^{\dagger}$ Colin A. Gould, $\neq$ Thierry Roisnel, $†$ \\ Stéphanie Delbaere, $\sim \sim$ Boris Le Guennic, ${ }^{\dagger}$ Denis Jacquemin, ${ }^{\#}$ and Stéphane Rigaut ${ }^{\dagger}$
}

Email: lucie.norel@univ-rennes1.fr

\author{
† Univ Rennes, INSA Rennes, CNRS, ISCR (Institut des Sciences Chimiques de Rennes) - UMR 6226, \\ F-35000 Rennes, France \\ $\wp$ Institut Universitaire de France, 1 rue Descartes, 75231 Paris, France \\ ¥Department of Chemistry, University of California, Berkeley, California 94720, United States \\ - University of Lille, UDSL, CNRS UMR 8516, BP83, Lille, France \\ Univ Lille, INSERM, CHU Lille, UMR-S 1172, Lille Neuroscience and Cognition Research Center, \\ F-59000, Lille, France \\ \# Univ. Nantes, CNRS, CEISAM UMR 6230, F-44000 Nantes, France
}

\begin{abstract}
We report the synthesis of a pyrazine-based bis-tridentate diarylethene (DAE) ligand and the corresponding dinuclear yttrium and dysprosium complexes that all show T-type photochromism. Large changes in the photochromic behaviour are induced by metal coordination, including a tuning of the bleaching rate by several orders of magnitude, characterized through VT-NMR and supported by theoretical calculations. The dysprosium dinuclear complex shows a single-molecule magnet (SMM) behaviour, under an external applied magnetic field, significantly modulated upon photoisomerization. This feature is further analyzed through ab initio calculations.
\end{abstract}

Keywords: diarylethene, lanthanide, NMR study, T-type photochromism, ab initio calculations, SingleMolecule-Magnet, photomagnetism.

\section{Introduction}

Photochromism, characterized by a reversible change of a substance color under light exposure [1], can be used for photoswitching of a fascinating range of properties [2-4], thanks to structural or electronic modifications with implications in catalysis [5], material sciences [6-8], medicine [9-10], information technologies [11], and many other fields. The dizzying list of potential and realized applications of photochromic units implies that the tailoring of the characteristics of a photochromic unit to adapt to a specific need should be mastered. For organic photochromism of $T$ type, for which the photoinduced state is metastable and thermally returns to the initial state, such characteristics include excitation wavelengths, quantum yields, fatigability, colorability and rate of thermal bleaching. Systems with fast bleaching are required for photochromic lenses or real-time holography [12-13], while for many biological applications, adaptation of the bleaching rate to meet specific process is key [10,14-15]. An extensive literature explores structure-properties relationships in hexaarylbiimidazole [16], spiropyrane and spirooxazine [17] or azobenzene [18-20] derivatives as well as less common molecules [21-22]. With some of these Tphotochromes, the impact of metal coordination on photoswitching has been explored and recognized as a valuable strategy to effectively adapt the system properties as well as to design sensors [23]. Metal coordination can, in other cases, block the photochromism, an effect that could be leveraged to enable gated photochromism [24-25].

In most cases, the ubiquitous diarylethene (DAE) photoswitches are considered as P-photochromes since the photoinduced closed isomer generally shows very long half-lives and can be transformed back to the 
initial open isomer with adequate light irradiation only [2]. However, this stability depends significantly on the nature of the central ethene bridge and, to a lesser extent, on the nature of the aryl groups and of their substitution patterns [26]. Typically, DAE with phenanthrene bridges [27-28] show low photoconversions and fast thermal bleaching of their closed isomer due to the loss of aromaticity upon photocyclisation. For example, a central fluorinated benzene ring can provide fast T-type photochromic DAE with a half-life of $130 \mathrm{~ms}$ at room temperature [29]. Recently, Diederich et al. demonstrated that DAE with a central pyrazine bridge like 2,3-bis(2,5-dimethylthiophen-3-yl)pyrazine are also T-photochromes with a thermal half-life of ca. one minute in acetonitrile [30]. Therefore, the pyrazine core that allows for coordination-induced tuning of photochromism, deserves to be further explored to extend this class of T-type DAEs.

This work also reports a further significant step towards the design of photoswitchable single-molecule magnets (SMMs) by combining the magnetic bistability of SMMs [31-34] with the light-switching ability of organic photochromes to provide a new family of photomagnetic systems [35-38]. We specifically target lanthanide-based complexes since their magnetic properties clearly stand out from those of transitionmetal complexes [39]. We previously obtained hysteresis photomodulation in DAE-dysprosium 1D assemblies [40] and decided to further investigate dinuclear complexes bridged by a DAE. Hence, we report here i) a newly synthesized pyrazine-based bis-tridentate DAE ligand and the corresponding dinuclear yttrium and dysprosium complexes that all show T-type photochromism, ii) large changes in the photochromic behaviour induced by metal coordination, with a tuning of the bleaching rate by several orders of magnitude characterized through VT-NMR and supported by theoretical calculations, and iii) the photomodulation of the resulting SMM properties upon photoisomerization, that is further analyzed through ab initio calculations.

\section{Results and Discussion}

Synthesis. Pyrazine-based photoswitches have been previously synthesized through the condensation of a bisthiophene dione and diamines to form the central pyrazine cycle [30]. Here, ligand BTP1 was conveniently synthesized by Suzuki coupling from 5-methyl-2-(pyridin-2-yl)-4-(4,4,5,5-tetramethyl-1,3,2dioxaborolan-2-yl)thiazole [41] and 2,3-dichloropyrazine in $78 \%$ yield. The optimized conditions for this coupling consist in the use of cesium fluoride together with $\operatorname{Pd}_{2}\left(\mathrm{dba}_{3}\right.$, tricyclohexylphosphonium tetrafluoroborate and potassium carbonate (Figure 1). Similarly, coupling between 2,5-dimethyl-4-(4,4,5,5tetramethyl-1,3,2-dioxaborolan-2-yl)thiophene and 2,3-dichloropyrazine afforded the previously published model compound BTP2 [30]. Then, BTP1 was put to react with 2 equivalents of $\left[\mathrm{M}(\mathrm{hfac})_{3} \cdot 2 \mathrm{H}_{2} \mathrm{O}\right](\mathrm{M}=$ $\mathrm{Y}, \mathrm{Dy}, \mathrm{hfac}=$ hexafluoroacetylacetonate $)$ in refluxing dichloromethane to afford the dinuclear compounds $\mathbf{1} \mathbf{M}_{\mathbf{o}}(\mathrm{M}=\mathrm{Y}$ or $\mathrm{Dy})$ as single crystals after slow cooling.

Single Crystal XRD structures. For BTP1 ${ }_{\mathbf{o}}$, Single crystals could be grown by slow evaporation of an acetone solution (Table S1). The compound crystallizes in the space group $P 2 c$ and the asymmetric unit consists of half a molecule, the other half being generated by a $C_{2}$ axis. The most striking feature of this structure is that the compound crystallizes in a non-photoreactive conformation with a distance between the two reactive carbons (C-Me) of 5.3820(3) $\AA$ and a parallel orientation of the two pyridylthiazolyl groups (Figure 2). Accordingly, no photocoloration of these crystals could be observed under UV light. Concerning the metal complexes, single crystals of $\mathbf{1} \mathbf{Y}_{\mathbf{o}}$ and $\mathbf{1} \mathbf{D} \mathbf{y}_{\mathbf{o}}$ are isostructural (space group C2/c). The dinuclear complexes also possess $C_{2}$ symmetry and the asymmetric unit is composed of half a complex. However, the participation of all three nitrogen atoms in a tridentate coordination pocket induces a very different geometry of the ligand in these complexes as compared with the ligand itself (Figure 2). The antiparallel conformation of the two thiazole rings as well as the short distance between the reactive carbons (3.375(5) $\AA$ for $\mathbf{1} \mathbf{Y}_{\mathbf{o}}, 3.369(12) \AA$ for $\mathbf{1} \mathbf{D y}_{\mathbf{o}}$ ) clearly indicates that a photocyclization reaction is not prevented by conformational issues for these two complexes [2]. However, upon UV irradiation, the crystals show no coloration, probably as a result of the low thermal stability of the closed form (see below) leading to a much faster bleaching rate than the photoisomerization one under these conditions (single crystal, RT). With the prospect of elucidating the magnetic behavior of the dysprosium compound, it is also important to pay attention to the metal ion environment in $\mathbf{1} \mathbf{D} \mathbf{y}_{\mathbf{o}}$. First, the coordination sphere around the Dy(III) ion is composed of three hexafluoroacetylacetonate ligands and three nitrogen atoms leading to a coordination number of 9. The dysprosium-oxygen bonds distances are relatively homogeneous in the range 2.342(6)-2.421(7) $\AA$, while the thiazole-nitrogen distance of 2.488(7) $\AA$ is clearly much shorter than the two other dysprosium-nitrogen distances (2.604(7) $\AA$ and 2.639(6) $\AA$ with the pyridine and pyrazine rings, respectively). The continuous shape measurement indicates a geometry close to a spherical- 
capped square antiprism (CShM parameter of 0.876, see ESI for details) [42]. Finally, the pyrazine core brings the two metal ions of the dinuclear compound in close vicinity (Dy-Dy distance of 7.8710(12) $\AA$ ). This is in the range for which substantial dipolar coupling can occur.<smiles>Clc1nccnc1Cl</smiles><smiles>[AlH2]c1ccccc1</smiles><smiles>Cc1sc(CC2CCCCC2)nc1-c1nccnc1-c1nc(-c2ccccn2)sc1C</smiles>

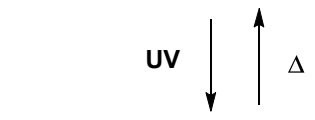<smiles>CC(C)(C)C12SC(c3ccccn3)=NC1=c1nccnc1=C1N=C(c3ccccn3)SC12C</smiles>

BTP2<smiles>Cc1cc(-c2nccnc2-c2cc(C)sc2C)c(C)s1</smiles>

$1 \mathrm{Mo}$

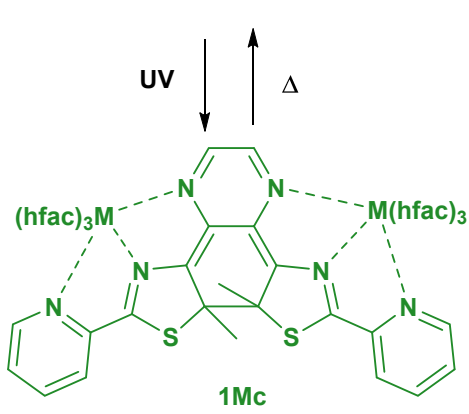

Figure 1. Synthesis and isomerization reactions of BTP1 and metal complexes $1 \mathbf{M}(\mathbf{M}=\mathrm{Y}, \mathrm{Dy})$. Conditions for step 1: toluene/water, $\mathrm{Pd}_{2}(\mathrm{dba})_{3}, \mathrm{HPCy}_{3} \mathrm{BF}_{4}, \mathrm{CsF}, \mathrm{K}_{2} \mathrm{CO}_{3}, 85^{\circ} \mathrm{C}$. Conditions for step 2: $\left.\left[\mathrm{M}(\mathrm{hfac})_{3} \cdot 2 \mathrm{H}_{2} \mathrm{O}\right)\right](\mathrm{M}=\mathrm{Y}, \mathrm{Dy})$, dichloromethane, reflux.
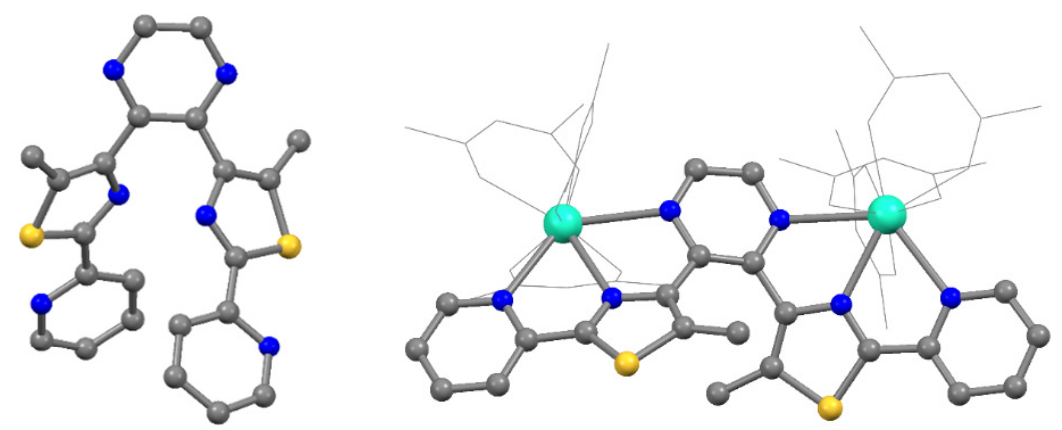

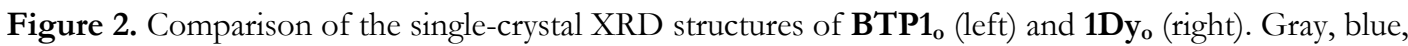
yellow and light blue spheres represent $\mathrm{C}, \mathrm{N}, \mathrm{S}$ and Dy atoms, respectively. $\mathrm{H}$ and $\mathrm{F}$ atoms are omitted and the hfac ligands are shown in wire style.

Study of photochromism by electronic absorption spectroscopy. Solutions of BTP1 $1_{\mathbf{o}}$ as well as reference $\mathbf{B T P 2} \mathbf{2}_{\mathbf{o}}$ in acetonitrile were measured at room temperature and the corresponding absorption spectra are reported in Figure S3. When these solutions were irradiated with a TLC illumination lamp at either $254 \mathrm{~nm}$ or $365 \mathrm{~nm}$, no coloration could be observed, and the absorption spectra remained

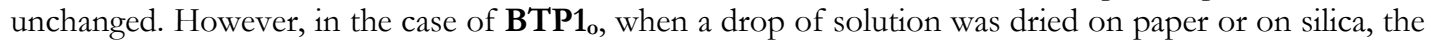


solid residue turned green upon UV irradiation with quick subsequent fading of the color when irradiation was stopped. We therefore reasoned that the lack of photochromism in solution was due to even quicker thermal fading, indicating that the closed system $\mathbf{B} \mathbf{T P} \mathbf{1}_{\mathbf{c}}$ is less stable than other classical DAE compounds. In dichloromethane and similar conditions, solutions of complexes $\mathbf{1} \mathbf{Y}_{\mathbf{o}}$ and $\mathbf{1} \mathbf{D} \mathbf{y}_{\mathbf{o}}$ do turn green under UV light and then progressive bleaching occurs after irradiation. The corresponding electronic absorption spectra are shown in Figure $\mathbf{3}$ (and $\mathbf{S} \mathbf{4}$ for $\mathbf{1} \mathbf{Y}_{\mathbf{o}}$.). If $\mathbf{B T P} \mathbf{1}_{\mathbf{c}}$ could not be observed at RT, the colored species $1 \mathbf{D y}_{\mathbf{c}}$ displaying the characteristic visible absorption of DAE could be detected by using a fast scan rate and the fast thermal reopening of the closed isomer was confirmed by the monoexponential decay $\left(\mathrm{t}_{1 / 2}=\right.$ $101 \mathrm{~s}$ ) of this visible absorption with time. The absorption maximum at $718 \mathrm{~nm}$ is clearly red-shifted as compared with previously published pyrazine-based DAEs $\left(643 \mathrm{~nm}\right.$ for $\mathbf{B T P 2} \mathbf{2}_{\mathbf{c}}$ ). For $\mathbf{1} \mathbf{Y}_{\mathrm{c}}$, the behavior was essentially identical to the one of $\mathbf{1} \mathbf{D y}_{\mathbf{c}}$ (see Figures $\mathbf{S} 4$ and S5). Overall, these experiments indicate that both $\mathbf{B T P 1} \mathbf{o}_{\mathbf{o}}$ and $\mathbf{1 M}_{\mathbf{o}}$ undergo photoisomerization reactions to lead to a closed isomer which is thermally unstable and undergo quick retrocyclization reaction at room temperature. However, the absence of photocoloration in solution in the case of $\mathbf{B T P} \mathbf{1}_{\mathbf{o}}$, clearly contrasting with the behavior of the metal complexes, suggests that the coordination significantly affects the thermal stability of the closed isomer. In order to quantitatively examine this effect, variable (low) temperature ${ }^{1} \mathrm{H}$ NMR spectroscopy was employed.

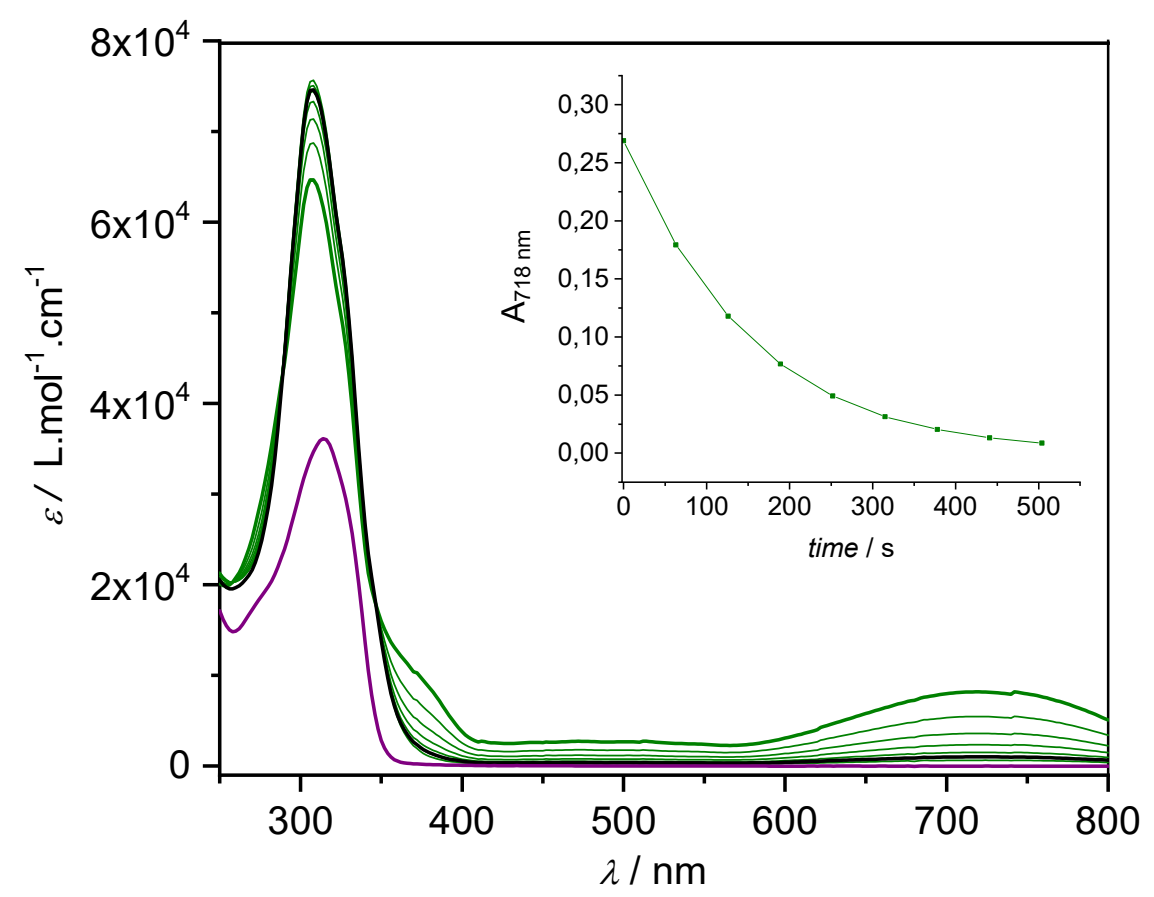

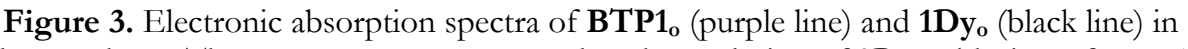
dichloromethane. The green spectra correspond to the evolution of $\mathbf{1} \mathbf{D y}_{\mathbf{c}}$ with time after $365 \mathrm{~nm}$ irradiation of a solution of $\mathbf{1} \mathbf{D y}_{\mathbf{o}}$. The inset shows the corresponding decrease of the absorbance at 718 $\mathrm{nm}$. Exponential fitting of this curve provides a half-life of $101 \mathrm{~s}$ at room temperature (around $26{ }^{\circ} \mathrm{C}$ ).

Study of photochromism by ${ }^{1} \mathbf{H}$ NMR spectroscopy at variable temperature. Solutions of BTP1 and $\mathbf{1} \mathbf{Y}_{\mathbf{o}}$ in $\mathrm{CD}_{2} \mathrm{Cl}_{2}$ were used for the NMR study. At $223 \mathrm{~K}$, the spectrum of $\mathbf{B T P 1} \mathbf{1}_{\mathbf{o}}$ is essentially the same as that obtained at room temperature and is consistent with the presence of one conformation in which the two halves of the molecule are magnetically equivalent. Upon irradiation with $313 \mathrm{~nm}$ light, the solution turned dark green and the ${ }^{1} \mathrm{H}$ spectrum consisted in a new set of resonances characterizing the formation of the expected cyclized $\mathbf{B} \mathbf{T P} \mathbf{1}_{\mathbf{c}}$ (80\% at PSS). For instance, in $\mathbf{B} \mathbf{T P} \mathbf{1}_{\mathbf{c}}$, the singlet signal at $2.30 \mathrm{ppm}(2.38$ ppm in $\mathbf{B T P 1} \mathbf{1}_{\mathbf{o}}$ ) was associated to the methyl groups and the pyrazine protons were observed at $7.71 \mathrm{ppm}$ (8.75 ppm in BTP1 $1_{\mathbf{o}}$ ), while the overall spectrum showed the preserved symmetry between the two halves of the molecule (Figure S6). The pyrazine proton signal is more shielded in the closed form due to the aromaticity loss of this pyrazine unit upon cyclization [30]. At $223 \mathrm{~K}$, no thermal evolution of the system 
was observed in the absence of light for $40 \mathrm{~min}$. Similarly, at $238 \mathrm{~K}$, the closed form of complex $\mathbf{1} \mathbf{Y}_{\mathrm{c}}$ could be generated by $365 \mathrm{~nm}$ irradiation (95\% at PSS) and its spectral features were similar, but clearly shifted, compared to those of $\mathbf{B T P} \mathbf{1}_{\mathbf{c}}$ owing to metal coordination. For instance, the methyl groups showed a single resonance at $2.38 \mathrm{ppm}$ and the pyrazine proton was observed at $7.33 \mathrm{ppm}$ (Figure 4 ). In addition to the unambiguous characterization of the closed isomers as the photogenerated products, NMR spectroscopy is quantitative and provides valuable information on the photoconversion and on the kinetic of thermal fading. So first, the photoconversion of $\mathbf{B T P} \mathbf{1}_{\mathbf{o}}\left(\boldsymbol{\lambda}_{\text {irr }}=313\right.$ and $365 \mathrm{~nm}$, for a purpose of comparison) and $1 \mathbf{Y}_{\mathbf{o}}\left(\lambda_{\text {irr }}=365 \mathrm{~nm}\right)$ at $238 \mathrm{~K}$, where no significant thermal back reaction occurred, was followed by recording ${ }^{1} \mathrm{H}$ NMR spectra between successive periods of illumination. In each spectrum, the integration of the singlet signals for the methyl groups in the open and cyclized forms were measured, allowing the time-evolution of concentrations to be determined (Figure 5). With the same irradiation wavelength of $365 \mathrm{~nm}$, a striking difference was observed between BTP1 and 1Y, with a PSS composition of $31 \%$ of $\mathbf{B T P} \mathbf{1}_{\mathbf{c}}$ and $69 \%$ of $\mathbf{B T P} \mathbf{1}_{\mathbf{o}}$ for the former and of $94 \%$ of $\mathbf{1} \mathbf{Y}_{\mathbf{c}}$ and $6 \%$ of $\mathbf{1} \mathbf{Y}_{\mathbf{o}}$ for the latter. The photoconversion is also much faster for the complex. A more efficient conversion of $\mathbf{B T P} \mathbf{1}_{\mathbf{o}}$ was reached upon irradiation at $313 \mathrm{~nm}$, as expected from the absorption profile (Figure 3).

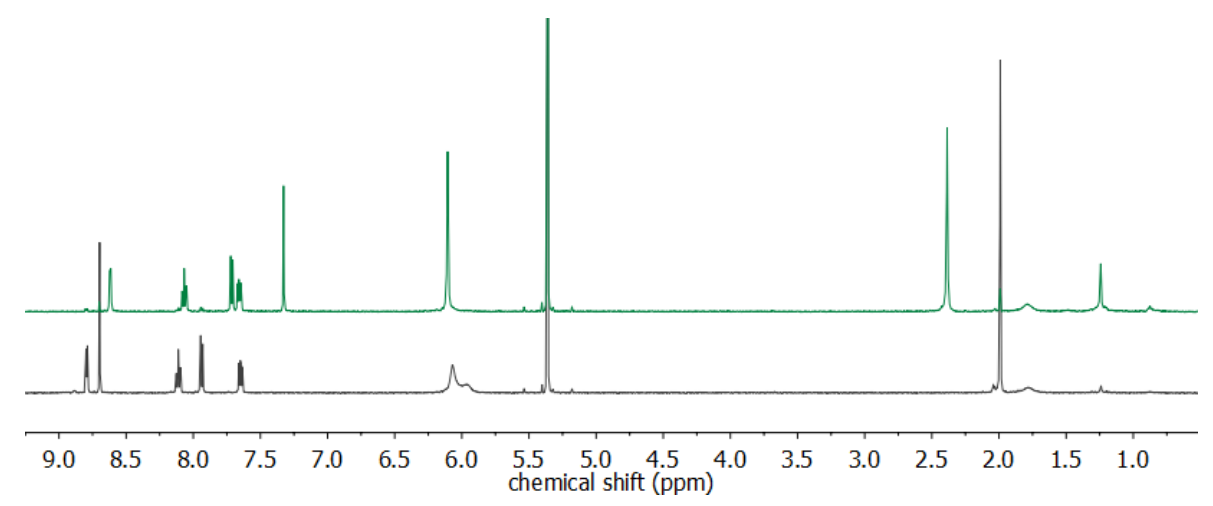

Figure 4. Comparison of the ${ }^{1} \mathrm{H}$ NMR spectra of $\mathbf{1} \mathbf{Y}_{\mathbf{o}}$ (bottom) and of $\mathbf{1} \mathbf{Y}_{\mathbf{c}}$ (top) in $\mathrm{CD}_{2} \mathrm{Cl}_{2}$ at $238 \mathrm{~K}$. The latter was obtained after irradiation at $365 \mathrm{~nm}$ for $10 \mathrm{~min}$ and showed $84 \%$ conversion.

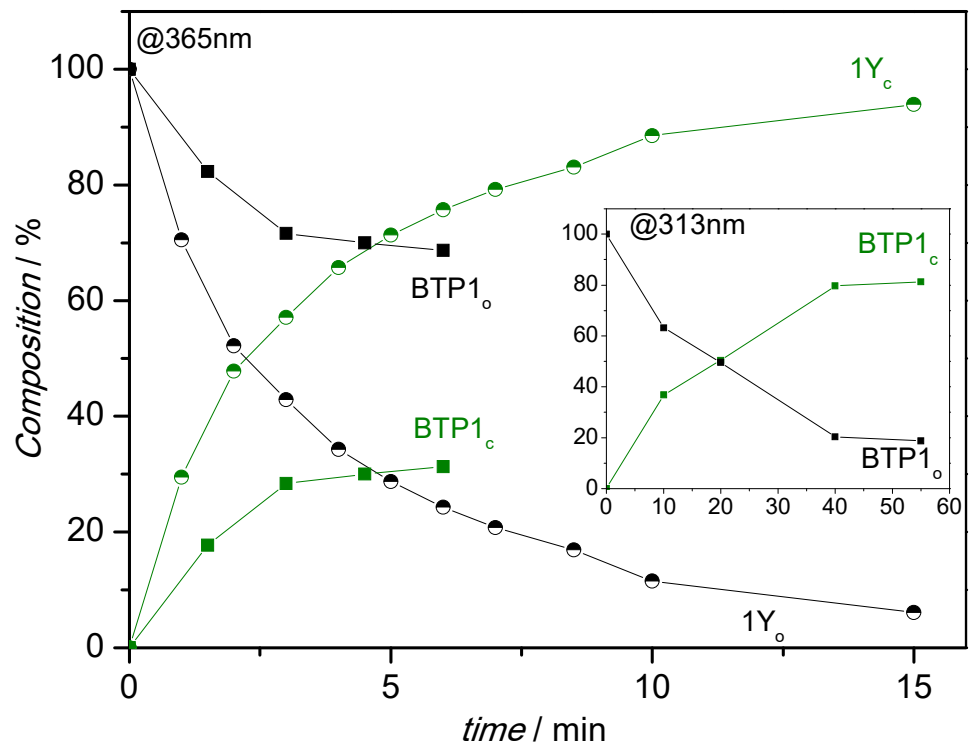

Figure 5. Photoconversion measured by ${ }^{1} \mathrm{H}$ NMR (see text) for BTP1 and 1Y with $365 \mathrm{~nm}$ irradiation or $313 \mathrm{~nm}$ irradiation (inset). 
The thermal relaxation was followed in the same way to determine the kinetic parameters of thermal fading

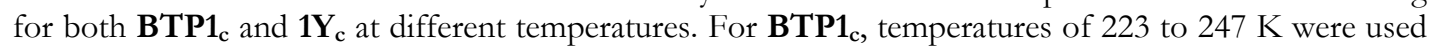
and the decrease in $\mathbf{B T P} \mathbf{1}_{\mathrm{c}}$ concentrations always followed a first-order law with the rate constants reported in Table 1. For $1 \mathbf{Y}_{\mathbf{c}}$, a similar behavior was observed ( $\mathrm{T}=260$ to $278 \mathrm{~K}$ ). Fitting of the first order kinetic constant temperature dependence with an Arrhenius law provides the frequency factor and activation energy for the cycloreversion reactions gathered in Table 1 . The obtained activation energies $\left(74 \mathrm{~kJ} \cdot \mathrm{mol}^{-1}\right.$

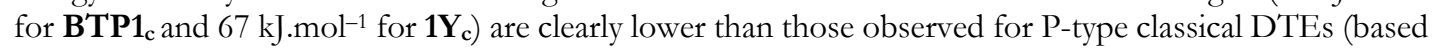
on the perfluorocyclopentene core) that show typical values as large as $140 \mathrm{~kJ} \cdot \mathrm{mol}^{-1}[2,26,43]$. They are nevertheless comparable to other fast bleaching systems like dithienyl thiazole derivatives [44] (80 to 90 $\left.\mathrm{kJ} \cdot \mathrm{mol}^{-1}\right)$, phenanthrene-based compounds [45] (50-60 kJ.mol-1) as well as perfluorobenzene-based compounds [29] $\left(66 \mathrm{~kJ} \cdot \mathrm{mol}^{-1}\right)$ and clearly reveal that the origin of this fast bleaching is the low stability of the closed form that correlates with low activation energies for the cycloreversion reaction. This is further confirmed by theoretical investigations (see below). However, the differences in kinetic stability between the ligand and the complex are clearly more governed by the 3000-fold decrease of the frequency factor when going from $\mathbf{B} \mathbf{T} \mathbf{P} \mathbf{1}_{\mathbf{c}}$ to $\mathbf{1} \mathbf{Y}_{\mathbf{c}}$. While the frequency factor observed for $\mathbf{B} \mathbf{T P} \mathbf{1}_{\mathbf{c}}$ compares quite well with other DTE systems (1.0 $10^{13} \mathrm{~s}^{-1}$ for 1,2-bis(2-methyl-5-phenyl-3-thienyl)perfluorocyclopentene with a stable closed form [26], $1.610^{10} \mathrm{~s}^{-1}$ for 1,2-bis(2,4-dimethyl-5-phenyl-3-thienyl)thiazolyl structure [44], 2.1 $10^{12} \mathrm{~s}^{-1}$ for 1,2-bis(2-methyl-5-phenyl-3-thienyl)tetrafluorobenzene), the frequency factor of $\mathbf{1} \mathbf{Y}_{\mathbf{c}}$ is much lower. This is clearly the main parameter explaining the increased kinetic stability of the closed form upon metal coordination. Kinetic stabilization by lanthanide coordination has been previously observed with terarylene switches [46]. The origin of this stabilization was also a change in the frequency factor. However, the effect observed in our work is a thousand times larger and could provide a new strategy for optimizing the photochromic performances of DAE derivatives. Clearly, further specific investigations are needed to be able to rationalize this effect. However, since variations of the electronic effects in otherwise similar organic structures can lead to a wide range of frequency factor (from $10^{9} \mathrm{~s}^{-1}$ to $10^{13} \mathrm{~s}^{-1}$ ) [47], we suggest that the involvement of nitrogen doublets in coordination bonds could play a role.

Table 1. Kinetic parameters extracted from ${ }^{1} \mathrm{H}$ NMR study. The decay of the closed isomer signal was fitted by a first order law. Arrhenius law fitting provides the frequency factor $\mathrm{A}$ and activation energy $\mathrm{E}_{\mathrm{a}}$ parameters.

\begin{tabular}{|c|c|c|c|c|c|}
\hline \multicolumn{3}{|c|}{$1 Y_{c}$} & \multicolumn{3}{|c|}{ BTP1c $_{c}$} \\
\hline $\mathrm{T}(\mathrm{K})$ & $\mathrm{k}\left(\mathrm{s}^{-1}\right)$ & $\begin{array}{c}\mathrm{A}\left(\mathrm{s}^{-1}\right) \\
\mathrm{E}_{\mathrm{a}}\left(\mathrm{kJ} \cdot \mathrm{mol}^{-1}\right)\end{array}$ & $\mathrm{T}(\mathrm{K})$ & $\mathrm{k}\left(\mathrm{s}^{-1}\right)$ & $\begin{array}{c}\mathrm{A}\left(\mathrm{s}^{-1}\right) \\
\mathrm{E}_{\mathrm{a}}\left(\mathrm{kJ} \cdot \mathrm{mol}^{-1}\right)\end{array}$ \\
\hline 252.7 & $9.2510^{-6}$ & & 223 & $9.0410^{-6}$ & \\
\hline 260 & $2.5110^{-5}$ & & 233 & $3.7810^{-5}$ & \\
\hline 262.75 & $4.0310^{-5}$ & $6.1410^{8}$ & 238.4 & $1.2310^{-4}$ & $1.9710^{12}$ \\
\hline 265 & $4.6010^{-5}$ & $66.69 \pm 4.20$ & 243 & $2.3410^{-4}$ & $74.20 \pm 6.14$ \\
\hline 272.3 & $9.4410^{-5}$ & $00.09 \pm 4.20$ & 247.12 & $4.1210^{-4}$ & $14.20 \pm 0.14$ \\
\hline 277.7 & $1.7110^{-4}$ & & & & \\
\hline
\end{tabular}

DFT study of BTP1. To obtain complementary insights, ab initio calculations were performed for BTP1 $\mathbf{1}_{\mathbf{o}}$ We used a "traditional" DFT approach, PCM- $\omega$ B97X/6-311G $(\mathrm{d}, \mathrm{p})$ to investigate the free energies of the different possible conformations (see Figure $\mathbf{6}$ and the SI for details) that are labeled depending on their symmetry : parallel $(P)$ or antiparallel $(A P)$. Functionals of the $\omega \mathrm{B} 97$ family have been shown to be accurate for various properties of DTE switches [48-49], and we computed the free energies using the harmonic vibrational frequencies. The most stable conformation $P 6$ presents the $C_{2}$ point group and shows a parallel orientation of the thiazolyl rings (Figure 6 ) that resembles the X-rays structure of $\mathbf{B T P} \mathbf{1}_{\mathbf{o}}$. According to a Boltzmann distribution, this conformation represents $88 \%$ of the conformers mixture at $298 \mathrm{~K}$ while the next two most stable isomers are $P 2\left(C_{1}\right.$ parallel conformation, $+5.2 \mathrm{~kJ} \cdot \mathrm{mol}^{-1}$ as compared to $\left.P O\right)$ and $A P 2$ $\left(C_{2}\right.$ antiparallel conformation, $\left.+10.3 \mathrm{~kJ} \cdot \mathrm{mol}^{-1}\right)$. This latter photoactive form represents $1.4 \%$ of the conformers' mixture at $298 \mathrm{~K}$ according to the calculations. We can therefore deduce that i) the lowtemperature NMR-detected conformer is $\mathrm{P} 6$ which presents a parallel conformation; ii) there should be a quick interconversion between the parallel and anti-parallel forms. The closed isomer was also investigated and different conformers corresponding to the rotation along the pyridyl-thiazolyl bond were computed. The most stable of these lies $138.9 \mathrm{~kJ} \cdot \mathrm{mol}^{-1}$ higher in energy than the reactive open conformation AP2. The transition state corresponding to the cycloreversion path was also computed, using a broken-symmetry 
approach with the same DFT level, and the corresponding activation energy $\left(69.0 \mathrm{~kJ} \cdot \mathrm{mol}^{-1}\right)$ matches very well the experimental one $\left(74.2 \mathrm{~kJ} \cdot \mathrm{mol}^{-1}\right)$. For the records, a M06-2X calculation yields a very similar value of $73.9 \mathrm{~kJ} \cdot \mathrm{mol}^{-1}$, such a difference of less than $5 \mathrm{~kJ} \cdot \mathrm{mol}^{-1}$ being in the BS-DFT error bar. Clearly, the reason for the fast bleaching of the closed form is the instability of $\mathbf{B T P} \mathbf{1}_{\mathbf{c}}$ and the consequent low cycloreversion activation energy as compared with classical DTE compounds.

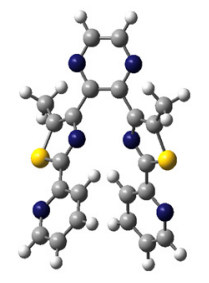

P6 (88.0\%)

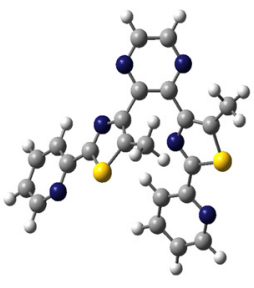

P2 (10.6\%)

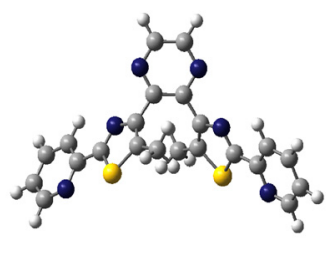

$A P 2(1.4 \%)$

Figure 6. DFT-optimized structures for the three most stable conformers BTP1 together with their Boltzmann weight as computed at RT (see Figure S15 in the SI for details).

Magnetic properties of $1 \mathrm{Dy}_{\mathrm{o}}$ and $1 \mathrm{D} \mathrm{y}_{\mathrm{c}}$. We further investigated a possible effect of photoisomerization on the SMM behavior of 1Dy by SQUID magnetometry. To allow reliable comparisons, three different samples were measured: i) synthesized single crystals of $\mathbf{1} \mathbf{D y}_{\mathbf{o}}$, ii) a photoconverted sample obtained by UV irradiation at low temperature of a dichloromethane solution of $\mathbf{1} \mathbf{D}_{\mathbf{o}}$ until reaching $91 \%$ conversion and solvent evaporation, named $\mathbf{1} \mathbf{D}_{\mathbf{y}^{\prime}}$, iii) the same sample measured after complete bleaching at room temperature and named $\mathbf{1} \mathbf{D}_{\mathbf{o}^{\prime}}$. Thus, the photomagnetic effect can be directly investigated with $\mathbf{1} \mathbf{D}_{\mathbf{y}^{\prime}}$ and 1D yo $^{\prime}$ because both samples have similar shaping and crystallinity. Indeed, with some exceptions [50], the solubilization and partial recrystallization of a SMM induce a change of their magnetic response that should not be mistaken with the targeted photomagnetic effect.

First, static magnetic measurements, which provide insight into the magnetic moment of the systems and possible magnetic coupling interactions, were performed on $\mathbf{1} \mathbf{D y}_{\mathbf{o}}$ (Figure $\mathbf{S 8}$ ). The room temperature value of the $\chi_{\mathrm{M}} \mathrm{T}$ product is $27.73 \mathrm{emu} . \mathrm{K}_{\mathrm{mol}} \mathrm{m}^{-1}$ in agreement with the expected value for two Dy ${ }^{\mathrm{III}}$ ions $\left(\chi_{\mathrm{M}} \mathrm{T}_{(300 \mathrm{~K})}=28.34\right.$ emu.K.mol$\left.{ }^{-1}, \mathrm{~g}_{\mathrm{J}}=4 / 3, \mathrm{~J}=15 / 2\right)$. Magnetization values at $2 \mathrm{~K}$ are also in agreement with the expected value for powder samples of non-interacting dimeric Dy ${ }^{\mathrm{III}}$ species and a monotonic evolution of $\chi_{M} T$ with temperature is observed (Figure S8).

Then, the SMM properties of the systems were characterized through dynamic magnetic measurements in which an oscillating magnetic field with variable frequency is used to trigger the system response. Note that at a molecular level, the two dysprosium centers in $\mathbf{1} \mathbf{D y}_{\mathbf{o}}$ are equivalent by symmetry and are expected to lead to the same magnetic relaxation. This should be true also for the closed complex since closing only occurs on conformers having $C_{2}$ antiparallel symmetry. On all samples clear frequency dependence of the out-of-phase susceptibility ( $\chi_{\mathrm{M}}$ "), a signature of a dynamic behavior of the magnetization, is observed between 1.8 and $9 \mathrm{~K}$ provided that an external magnetic field $\left(\mathrm{H}_{\mathrm{dc}}\right)$ is applied (Figures 7 and S9-S12). The optimal field is $\mathrm{H}_{\mathrm{dc}}=1200$ Oe for all samples. This is associated with slow relaxation of the magnetization related to the SMM behavior of each sample investigated. This behavior can be further characterized by extracting the systems relaxation times $(\tau)$ using a modified Debye law [51] that considers four different types of magnetic relaxation (Figures 8 and S13-S14):

$$
\tau^{-1}=\tau_{\text {direct }^{-1}}+\tau_{\text {tunnel }^{-1}}+\tau_{\text {Raman }^{-1}}+\tau_{\text {Orbach }^{-1}}(\mathbf{1})
$$

In this equation, each term relates to a different mechanism for relaxation, namely direct relaxation, quantum tunneling of magnetization, Raman relaxation and Orbach mechanisms that have different temperature dependence as follow:

$$
\tau^{-1}=\tau_{\text {direct }^{-1}}+\tau_{\text {tunnel }^{-1}}+\mathrm{CT}^{\mathrm{n}}+\tau_{0}^{-1} \exp \left(-\mathrm{U}_{\text {eff }} / \mathrm{k}_{\mathrm{B}} \mathrm{T}\right)(\mathbf{2})
$$


On our series of samples, the fitting procedure shows that magnetic relaxation is governed by Raman and tunnel relaxations (see experimental section for the details). The following parameters have been obtained in agreement with what is found in the literature $\left(\mathbf{1 D y}_{\mathbf{o}}: \mathrm{C}=0.110 \pm 0.005 \mathrm{~s}^{-1} \mathrm{~K}^{-1}, \mathrm{n}=6.03 \pm 0.06\right.$, $\tau_{\text {tunnel }}=0.190 \pm 0.003 \mathrm{~s} ; 1 \mathbf{D y}_{\mathrm{c}^{\prime}}: \mathrm{C}=6.71 \pm 0.60 \mathrm{~s}^{-1} \mathrm{~K}^{-1}, \mathrm{n}=3.49 \pm 0.07, \tau_{\text {tunnel }}=9.3 \pm 0.2610^{-3} \mathrm{~s} ; 1 \mathbf{D y}_{\mathbf{o}^{\prime}}$ : $\left.\mathrm{C}=0.61 \pm 0.05 \mathrm{~s}^{-1} \mathrm{~K}^{-1}, \mathrm{n}=4.85 \pm 0.08, \tau_{\text {tunnel }}=41 \pm 0.810^{-3} \mathrm{~s}\right)[33,52]$. From this analysis, it is visible that the less crystalline materials $\left(\mathbf{1} \mathbf{D y}_{\mathbf{c}^{\prime}}\right.$ and $\left.\mathbf{1} \mathbf{D} \mathbf{y}_{\mathbf{o}^{\prime}}\right)$ relax faster than the crystalline one $\left(\mathbf{1} \mathbf{D} \mathbf{y}_{\mathbf{o}}\right)$ and that all the magnetic relaxation properties are different between $\mathbf{1} \mathbf{D} \mathbf{y}_{\mathbf{o}}$ and $\mathbf{1} \mathbf{D} \mathbf{y}_{\mathbf{o}^{\prime}}$ mainly because of the crystallinity difference between the two samples. But the main information from the dynamic magnetic measurements is that when photoconversion is performed on two samples with similar shaping and crystallinity $\left(\mathbf{1 D}_{\mathbf{y}^{\prime}}\right.$ and $\mathbf{1} \mathbf{D}_{\mathbf{y}^{\prime}}$ ) a significant acceleration of the magnetic relaxation is observed when going from the closed to the open form (Figure 8).

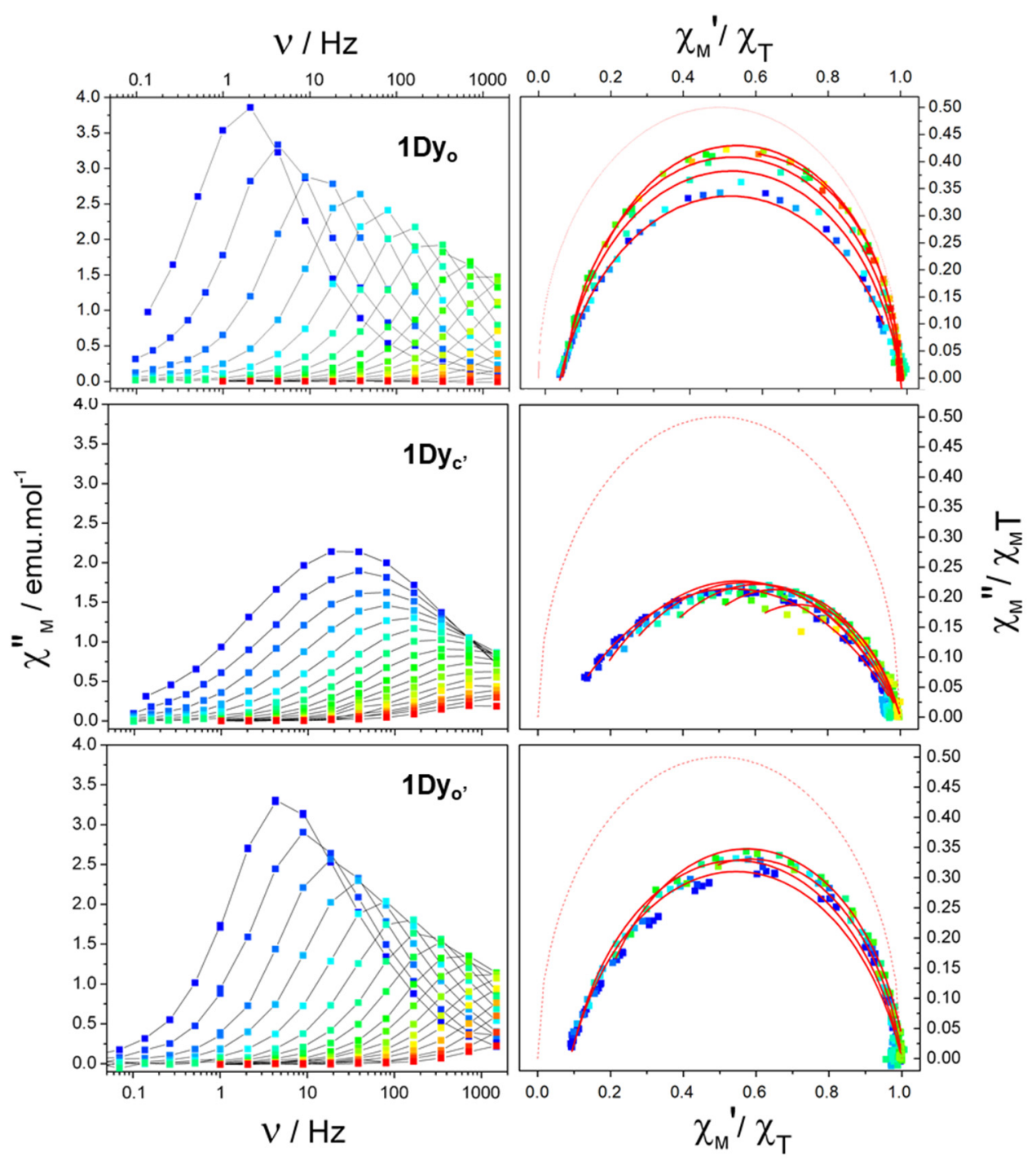

Figure 7. (left) Frequency dependence of the out-of-phase magnetic susceptibility $\chi_{\mathrm{M}}$ " of $1 \mathbf{D y}_{\mathbf{o}}, 1 \mathbf{D} \mathbf{y}_{\mathbf{c}^{\prime}}$ and $1 \mathbf{D y}_{\mathbf{o}^{\prime}}$ (from top to bottom) measured with a static magnetic field $\mathrm{H}_{\mathrm{dc}}=1200$ Oe between $2 \mathrm{~K}$ (blue) and $10 \mathrm{~K}$ (red). (right) Corresponding Cole-Cole plots with some of the best fits as red full lines and ideal relaxation curve $(\alpha=0, \mathrm{RF}=100 \%)$ as red dotted line. 


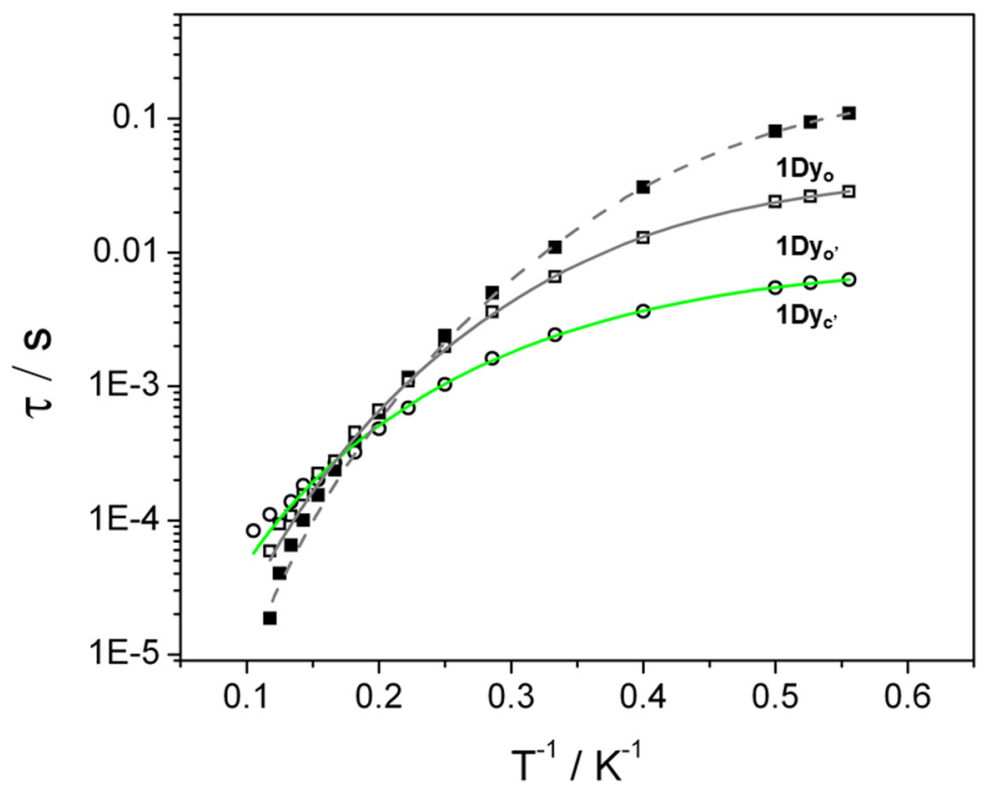

Figure 8. Arrhenius plot of the relaxation times measured for $\mathbf{1} \mathbf{D y}_{\mathbf{o}}, \mathbf{1} \mathbf{D} \mathbf{y}_{\mathbf{o}^{\prime}}$ and $\mathbf{1} \mathbf{D} \mathbf{y}_{\mathbf{c}^{\prime}}$ with best fits (Raman + Tunnel) as dotted grey line, full grey line, and full green line, respectively

(see Table S2 for values).

Another useful parameter to characterize the magnetic relaxation of a molecule is the distribution $(\alpha)$ of its relaxation times. This parameter is extracted from Cole-Cole plots (Figure 7, Tables 2 and S3-S8) and is expected to be 0 if all molecules relax simultaneously and 1 on the contrary (spin glass-like behavior). Additionally, from the difference between the measured and the ideal Cole-Cole plot, the relaxing fraction (RF) that is the part of the sample that relaxes slowly, can be extracted $\left(R F=1-\left(\chi_{s} / \chi_{T}\right)\right.$, with $\chi_{s}$ being the adiabatic and $\chi_{\mathrm{T}}$ the isothermal susceptibility). For $1 \mathbf{D} \mathbf{y}_{\mathrm{o}}$ as expected, almost all the sample relaxes slowly and $\mathrm{RF}_{(2 \mathrm{~K})}=$ $94 \%$ and $\mathrm{RF}_{(7 \mathrm{~K})}=87 \%$. This is associated with quite low $\alpha$ values of $\alpha_{(2 \mathrm{~K})}=0.21$ and $\alpha_{(7 \mathrm{~K})}=0.02$. In the photoisomerized sample (1- $\left.\mathbf{D y}_{\mathbf{c}^{\prime}}\right)$, the relaxing fraction diminishes, especially in the high temperature region with $\mathrm{RF}_{(2 \mathrm{~K})}=93 \%$ and $\mathrm{RF}_{(7 \mathrm{~K})}=56 \%$ and the distribution of the relaxation times is severely increased with $\alpha_{(2 \mathrm{~K})}=$ 0.45 and $\alpha_{(7 \mathrm{~K})}=0.25$. This is combined with a peak broadening in the $\chi_{\mathrm{M}}$ " vs. frequency curves (Figure 7) as often observed when non-purely crystalline samples are compared to crystalline material. When $\mathbf{1} \mathbf{D}_{\mathbf{y}^{\prime}}$ is converted back to $\mathbf{1} \mathbf{D y}_{\mathbf{o}^{\prime}}$, the complex relaxes fairly well when compared to $1 \mathbf{D y}_{\mathbf{c}^{\prime}}\left(\mathrm{RF}_{(2 \mathrm{~K})}=91 \%, \mathrm{RF}_{(7 \mathrm{~K})}=\right.$ $83 \%, \alpha_{(2 \mathrm{~K})}=0.24$ and $\left.\alpha_{(7 \mathrm{~K})}=0.15\right)$ and peak broadening is diminished. However, all its relaxing properties are not recovered when compared to the crystalline sample $\mathbf{1 D} \mathbf{y}_{\mathbf{o}}$. These differences could be ascribed to a distribution of slightly different coordination Dy ${ }^{\mathrm{III}}$ geometries in the less crystalline compounds as compared with $1 \mathbf{D y}_{\mathbf{0}}$.

Overall, a clear finding of these magnetic measurements is that the closing reaction induces an acceleration of the magnetic relaxation $(\tau)$, an increase of the relaxation time distribution $(\alpha)$ and a diminution of the relaxation fraction in the high-temperature regime when $\mathbf{1} \mathbf{D}_{\mathbf{y}^{\prime}}$ is compared with the open analogue (1D $\left.\mathbf{y}_{\mathbf{o}^{\prime}}\right)$. Moreover, as observed in our previous studies, these magnetic measurements confirm that the effect of photoconversion on the SMM behavior of magnetic molecules has to be investigated on comparable sampling, i.e. single crystals when single-crystal to single-crystal photoconversion is observed [40] or evaporated solution when photoconversion occurs at the liquid state [53].

Table 2. Table of relaxation time distribution parameters measured for $\mathbf{1} \mathbf{D} \mathbf{y}_{\mathbf{o}}, \mathbf{1} \mathbf{D} \mathbf{y}_{\mathbf{c}^{\prime}}$ and $\mathbf{1} \mathbf{D} \mathbf{y}_{\mathbf{o}^{\prime}}\left(\mathrm{H}_{\mathrm{dc}}=1200\right.$ $\mathrm{Oe})$.

\begin{tabular}{lllll}
\hline & \multicolumn{2}{l}{ Relaxing fraction, $\mathrm{RF}$} & \multicolumn{2}{l}{ Relaxation time distribution, $\alpha$} \\
& $\mathrm{RF}_{(2 \mathrm{~K})} \%$ & $\mathrm{RF}_{(7 \mathrm{~K})} \%$ & $\alpha_{(2 \mathrm{~K})}$ & $\alpha_{(7 \mathrm{~K})}$ \\
1Dyo & 94 & 87 & 0.21 & 0.02 \\
1D $_{\mathbf{c}^{\prime}}$ & 93 & 56 & 0.45 & 0.25 \\
1D $_{\mathbf{y}_{\mathbf{o}^{\prime}}}$ & 91 & 83 & 0.24 & 0.15 \\
\hline
\end{tabular}


Electronic Structure and Computed Magnetic Properties of $1 \mathrm{Dy}_{\mathrm{o}}$ and $1 \mathrm{Dy}_{\mathbf{c}}$. We further analyzed the effect of isomerization on the magnetic properties through ab initio calculations (see SI for details). The calculated relative energies of the lowest Kramers doublet states deriving from the ${ }^{6} \mathrm{H}_{15 / 2}$ level of the isolated $\mathrm{Dy}^{3+}$ ions in the open and closed forms of $\mathbf{1 D y}$ are given in Table S10. For the open isomer, both

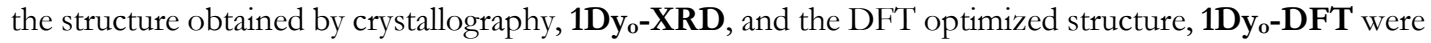
considered. The ground state (GS) wavefunction of $\mathbf{1} \mathbf{D y}_{\mathbf{o}}-\mathbf{X R D}$ corresponds principally (91\%) to the $\mathbf{M}_{\mathrm{J}}$ $= \pm 15 / 2$ component, with a sizable admixture of ca. $4 \%$ with the $M_{J}= \pm 9 / 2$ component. Such admixture leads to a decrease of the magnetic anisotropy with calculated g-factors of $0.1,0.5$ and 18.9, and a local easy magnetic axis crossing one of the hfac ligand as shown in Figure 9. The first excited state (ES) is located $39 \mathrm{~cm}^{-1}$ above the GS and, despite a similar magnetic anisotropy, it corresponds to a large admixture of several $\mathrm{M}_{\mathrm{J}}$ components with an easy magnetic axis almost perpendicular to that of the GS $(\theta$ $=86.8^{\circ}$ ). The use of $\mathbf{1} \mathbf{D} \mathbf{y}_{\mathbf{o}}-\mathbf{D F T}$ instead of $\mathbf{1} \mathbf{D} \mathbf{y}_{\mathbf{o}}-\mathbf{X R D}$ for the wavefunction theory calculations alters the nature of the GS, with a slightly more Ising character $\left(95 \% \mathrm{M}_{\mathrm{J}}= \pm 15 / 2\right)$. The first ES is destabilized energetically and its nature is strongly affected by the structural changes, with a decrease in magnitude of the easy magnetic axis and a different orientation with respect to the GS easy magnetic axis $\left(\theta=53.7^{\circ}\right)$. We could also perform geometry optimization of the closed form, which shows the expected features of a ring-closed isomer with for instance a $\mathrm{C}-\mathrm{C}$ bond between reactive carbons of $1.55 \AA$ and an overall planarization of the ligand with an angle of $3^{\circ}\left(v s .56^{\circ}\right.$ in $1 \mathbf{D y}_{0}-\mathbf{D F T}$ ) between the planes of the two thiazoles ligands. In comparison with the open isomer, the GS in the closed form $\mathbf{1 D} \mathbf{y}_{\mathbf{c}}-\mathbf{D F T}$ remains strongly $\mathrm{M}_{\mathrm{J}}= \pm 15 / 2(92 \%)$ despite a large re-organization of the coordination sphere. The principal changes between the open and closed forms are seen in the first excited state, with a larger magnetic

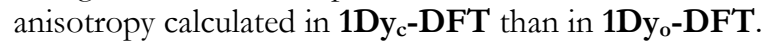
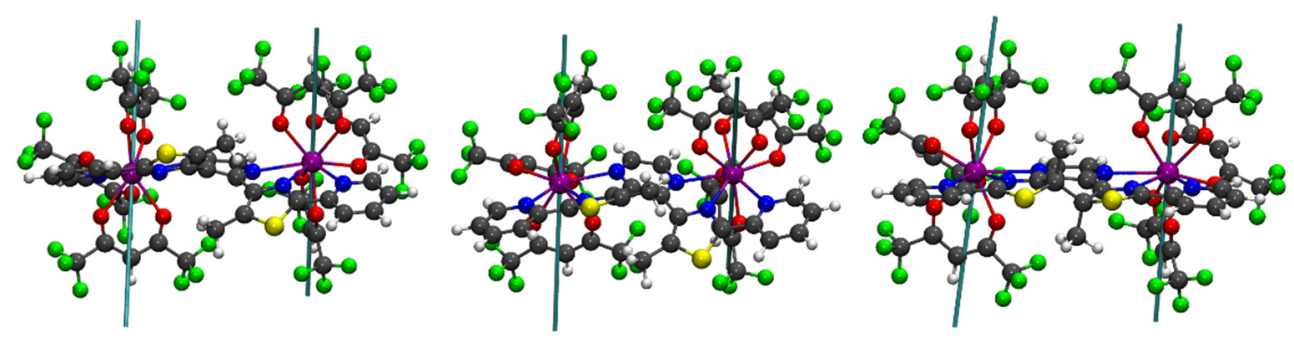

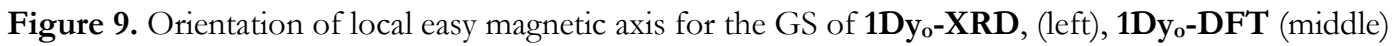
and $1 \mathbf{D y}_{\mathbf{c}}$-DFT (right).

The calculated magnetic susceptibility $(\chi T)$ and magnetization $(M)$ for the open and closed forms of $1 \mathrm{Dy}$ are shown in Figure S17. As expected from the similar electronic structures, the calculated static magnetic properties for the investigated compounds are almost identical between each other and reproduce properly the experimental data. At very low temperature, an intramolecular antiferromagnetic interaction between the $\mathrm{Dy}^{3+}$ ions is found to be responsible for the decrease of the $\chi \mathrm{T}$ product. Using the dipolar approximation, isotropic dipolar magnetic coupling constants $\left(J_{\text {iso }}^{\text {DIP }}\right)$ of $-0.070,-0.059$ and $-0.081 \mathrm{~cm}^{-1}$ are calculated for $\mathbf{1} \mathbf{D y}_{\mathbf{o}}-\mathbf{X R D}, \mathbf{1} \mathbf{D y}_{\mathbf{o}}-\mathbf{D F T}$ and $\mathbf{1} \mathbf{D y}_{\mathbf{c}}-\mathbf{D F T}$, respectively. Interestingly, the representation of

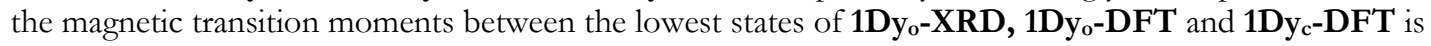
found to be very sensitive to the structural changes (see Figure 10), suggesting possibly different dynamic magnetic properties. It is particularly interesting to look at possible Orbach mechanisms since we could not extract such information from the experimental data. In the three structures, an Orbach mechanism for the relaxation of the magnetization through ES1 is favored, suggesting slow relaxation of magnetization

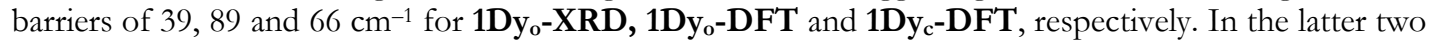
systems, thermally-assisted quantum tunneling relaxation mechanisms start to be non-negligible in ES1 with calculated transversal magnetic transition moment of 1.53 and $0.65 \mu \mathrm{B}$, respectively. In $1 \mathbf{D y}_{\mathbf{o}}-\mathbf{X R D}$, the transversal Orbach mechanism is the dominant one because of the almost perpendicular orientation of the GS and ES1 easy magnetic axes. However, it has to be mentioned that the GS in $\mathbf{1 D} \mathbf{y}_{\mathbf{o}}-\mathbf{X R D}$ already exhibits strong QTM, suggesting possible fast relaxation, in line with the fact that no slow relaxation is observed in zero applied external field. This stronger QTM mechanism compared to $\mathbf{1 D} \mathbf{D}_{\mathbf{o}}-\mathbf{D F T}$ is

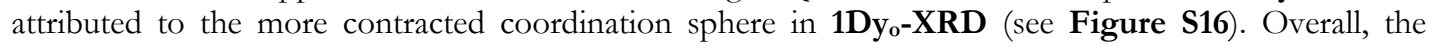


opening or closing of the bridging ligand does not drastically modify the dipolar magnetic coupling between the two metallic centers. However, the structural re-organization of this central ligand leads to sizable changes in the coordination sphere around the Dy centers that induces modifications of the crystalfield splitting of the ${ }^{6} \mathrm{H}_{15 / 2}$ level, and hence of the magnetic relaxation pathways.
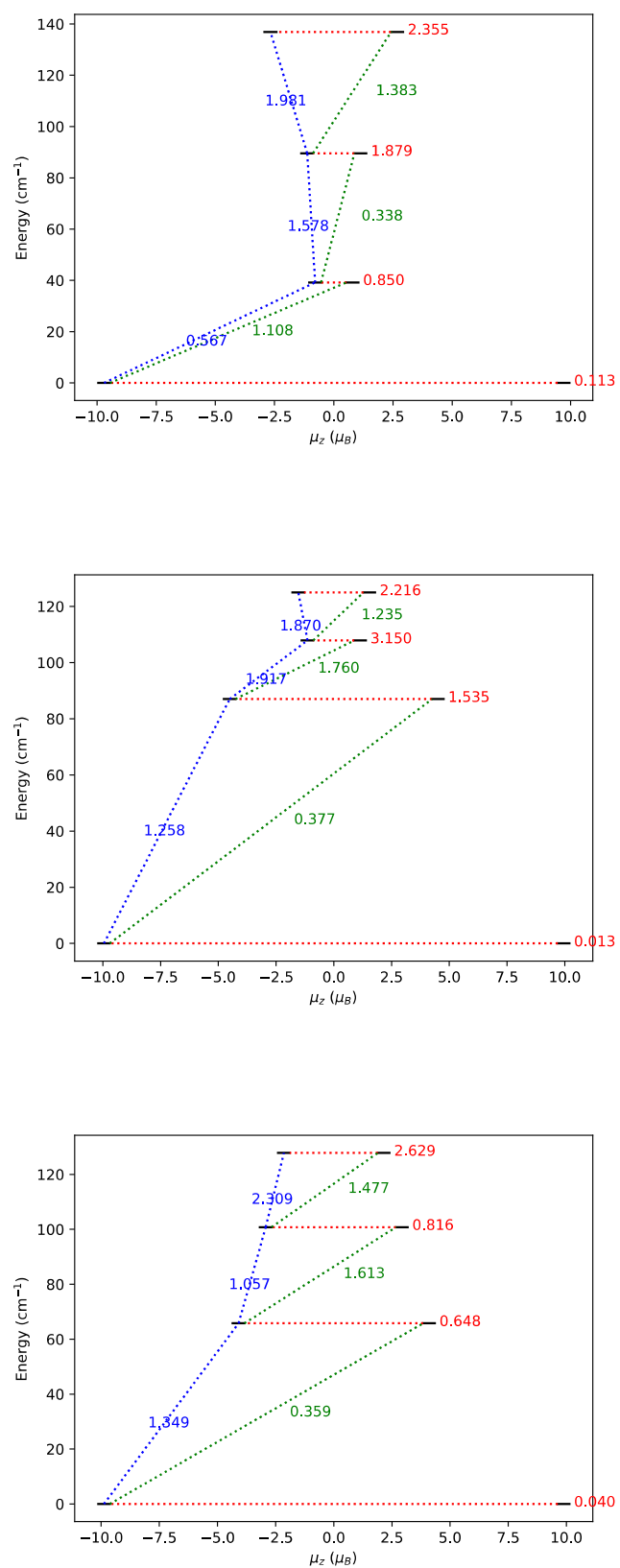

Figure 10. Energies (in $\mathrm{cm}^{-1}$ ) and projected $\mu_{\mathrm{z}}$ (in $\mu_{\mathrm{B}}$ ) values along the ground magnetic axis for the lowest states of $\mathbf{1} \mathbf{D y}_{\mathbf{o}}-\mathbf{X R D}$ (top), $\mathbf{1} \mathbf{D} \mathbf{y}_{\mathbf{o}}-\mathbf{D F T}$ (middle) and $\mathbf{1} \mathbf{D y}_{\mathbf{c}}-\mathbf{D F T}$ (bottom). The values of the magnetic (i.e. isotropic Zeeman) transition moments between the states are given for comparison. The values in horizontal correspond to QTM (for the GS) and TA-QTM (for the ESs) mechanisms of the magnetization relaxation, whereas vertical and diagonal values correspond to Orbach mechanisms. 
III

Conclusions

We have designed a new pyrazine-core DAE ligand with fast T photochromism that exhibits a large change of bleaching time upon metal coordination with slower kinetic allowing its observation and use for properties control. In particular, the dysprosium complex shows a rare example of lanthanide dinuclear complex bridged by a photochromic ligand [38] and allows to study the impact of the isomerization on the slow relaxation of magnetization. We demonstrated both experimentally and theoretically that the main effect explaining the slower bleaching rate in the complexes is a change in the frequency factor of several orders of magnitude. We believe that this could provide a new strategy for optimizing the photochromic performances of DAE derivatives and we are currently implementing changes in the metal ion precursors in order to fully explore this effect.

\section{Additional Information}

Supporting information is available online. Correspondence and requests for materials should be addressed to the corresponding author.

\section{Materials and Methods}

See supporting information for complete details about the synthesis and NMR spectra.

2,3-bis(5-methyl-2-(pyridine-2-yl)thiazol-4-yl)pyrazine, BTP1 $1_{0}$ In a Schlenk tube were degassed under vacuum for 1 hour, 5-methyl-2-(pyridin-2-yl)-4-(4,4,5,5-tetramethyl-1,3,2-dioxaborolan-2-yl)thiazole [41] (754 mg, $2.49 \mathrm{mmol}), 2,3$-dichloropyrazine (139 mg, $0.93 \mathrm{mmol}), \mathrm{Pd}_{2}(\mathrm{dba})_{3}(73 \mathrm{mg}, 0.08 \mathrm{mmol})$, tricyclohexylphosphonium tetrafluoroborate $(59 \mathrm{mg}, 0.16 \mathrm{mmol})$, cesium fluoride $(1.09 \mathrm{~g}, 7.17 \mathrm{mmol})$ and potassium carbonate $(40 \mathrm{mg}, 0.29 \mathrm{mmol})$. The solids were then dissolved in a mixture of toluene $(20 \mathrm{~mL})$ and water $(5 \mathrm{~mL})$, previously degassed by argon bubbling. The resulting reaction mixture was heated at $85^{\circ} \mathrm{C}$ for $67 \mathrm{~h}$ and then cooled to room temperature. After the addition of water $(50 \mathrm{~mL})$, extraction with ethyl acetate $(2 \times 50 \mathrm{~mL})$ was performed. The organic phase was filtered through a plug of celite. The celite cake was washed several times with ethyl acetate and the combined organic phases were evaporated under reduced pressure. The obtained brown oil was purified by column chromatography (silica, chloroform acetone $(0->25 \%))$. The product was then isolated as a beige solid $(311 \mathrm{mg}, 0.73 \mathrm{mmol}, 78 \%) .{ }^{1} \mathrm{H}$ NMR $\left(400 \mathrm{MHz}, \mathrm{CDCl}_{3}\right): \delta 8.68(\mathrm{~s}, 2 \mathrm{H}), 8.48(\mathrm{ddd}, J=4.9,1.8,0.9 \mathrm{~Hz}, 2 \mathrm{H}), 7.83(\mathrm{dt}, J=8.0,1.2 \mathrm{~Hz}, 2 \mathrm{H}), 7.56$ $\left(\mathrm{td}, J_{a v}=7.7,1.8 \mathrm{~Hz}, 2 \mathrm{H}\right), 7.17(\mathrm{ddd}, J=7.5,4.9,1.2 \mathrm{~Hz}, 2 \mathrm{H}), 2.44(\mathrm{~s}, 6 \mathrm{H}) .{ }^{13} \mathrm{C}$ NMR $\left(101 \mathrm{MHz}, \mathrm{CDCl}_{3}\right): \delta$ 164.6, 151.2, 149.5, 149.2, 148.9, 142.5, 136.9, 136.6, 124.2, 119.3, 12.45. FT-IR $\left(\mathrm{cm}^{-1}\right.$, ATR $)=1582(\mathrm{~m})$, $1564(\mathrm{~m}) 1452$ (m) 1431 (s), 1294 (m), 1271 (m) 1016 (m), 995 (m), 983 (m), 858 (m), 777 (s). HRMS (m/ g) $[\mathrm{M}+\mathrm{H}]^{+}=429.0953$ (calcd 429.09506), $\mathrm{M}^{+}=428.0874$ (calcd 428.08724). Elemental analysis calcd (\%) for $\mathrm{C}_{22} \mathrm{H}_{16} \mathrm{~N}_{6} \mathrm{~S}_{2}$ : C 61.66; H 3.76; N 19.61, S 14.96; found C 61.53; H 3.77; N 19.40, S 14.80.

Complex 1Dyo : 2,3-bis(5-methyl-2-(pyridine-2-yl)thiazol-4-yl)pyrazine (57.0 mg, $0.13 \mathrm{mmol}, 1 \mathrm{eq}$.) and [Dy(hfac) $\left.)_{3} 2 \mathrm{H}_{2} \mathrm{O}\right)$ ] [54] $(213.0 \mathrm{mg}, 0.26 \mathrm{mmol}, 2$ eq.) were mixed in $10 \mathrm{~mL}$ of dichloromethane and the mixture was refluxed for $15 \mathrm{~min}$ to observe complete solubilization. Upon slow cooling, block shaped crystals were obtained $(61 \mathrm{mg})$. A second crop of similar crystals was obtained after cooling at $-20^{\circ} \mathrm{C}$. The total yield was $142 \mathrm{mg}(0.07 \mathrm{mmol}, 55 \%)$. FT-IR $\left(\mathrm{cm}^{-1}\right.$, ATR $)=1651\left(\mathrm{~s}, \mathrm{v}_{\mathrm{C}=\mathrm{O}}\right), 1501(\mathrm{~m}), 1479(\mathrm{~m}), 1250$ (s), $1203(\mathrm{~s}), 1196(\mathrm{~m}), 1136(\mathrm{vs}), 783(\mathrm{~m})$. HRMS (m/ z) By high resolution mass spectrometry (ESI) were detected the ions $\left[\mathrm{C}_{22} \mathrm{H}_{16} \mathrm{~N}_{6} \mathrm{~S}_{2} \mathrm{Dy}(\mathrm{hfac})_{2}\right]^{+}$with $(\mathrm{m} / \mathrm{z})=1005.9920(\mathrm{calcd} 1005.99257)$ and $[\mathrm{Dy}(\mathrm{hfac})]^{-}$with $(m / z)=991.8818$ (calcd 991.88203). Elemental analysis calcd (\%) for $\mathrm{C}_{52} \mathrm{H}_{22} \mathrm{~N}_{6} \mathrm{O}_{12} \mathrm{~F}_{36} \mathrm{~S}_{2} \mathrm{D} y_{2}: \mathrm{C} 31.29 ; \mathrm{H}$ 1.11; N 4.21, S 3.21; found C 32.44; H 1.10; N 4.10, S 3.45.

Complex 1Y $\mathbf{Y}_{\mathbf{o}}$ : 2,3-bis(5-methyl-2-(pyridine-2-yl)thiazol-4-yl)pyrazine (45,2 $\left.\mathrm{mg}, 0,11 \mathrm{mmol}, 1 \mathrm{eq}.\right)$ and $\left.\left[\mathrm{Y}(\mathrm{hfac})_{3} \cdot 2 \mathrm{H}_{2} \mathrm{O}\right)\right](150,1 \mathrm{mg}, 0,21 \mathrm{mmol}, 2$ eq.) were mixed in $10 \mathrm{~mL}$ of dichloromethane and the mixture was refluxed for $15 \mathrm{~min}$ to observe complete solubilization. Crystals were obtained by slow evaporation. The yield was $42 \mathrm{mg}(0.023 \mathrm{mmol}, 21 \%)$. FT-IR $\left(\mathrm{cm}^{-1}\right.$, ATR $)=1653\left(\mathrm{~s}, \mathrm{v}_{\mathrm{C}=\mathrm{O}}\right), 1501(\mathrm{~m}), 1477(\mathrm{~m}), 1253$ 
(s), 1203 (s), 1196 (m), 1139 (vs), 783 (m). HRMS (m/z) : By high resolution mass spectrometry (ESI) were detected the ions $\left[\mathrm{C}_{22} \mathrm{H}_{16} \mathrm{~N}_{6} \mathrm{~S}_{2} \mathrm{Y}(\mathrm{hfac})_{2}\right]^{+}$with $(\mathrm{m} / \mathrm{z})=930.9692($ calcd 930.96924$)$ and $\left[\mathrm{Y}(\mathrm{hfac})_{4}\right]^{-}$with $(\mathrm{m} / \mathrm{z})$ $=916.8581$ (calcd 916.8581). Elemental analysis calcd (\%) for $\mathrm{C}_{52} \mathrm{H}_{22} \mathrm{~N}_{6} \mathrm{O}_{2}{ }_{2} \mathrm{~F}_{36} \mathrm{~S}_{2} \mathrm{Y}_{2}$ : C 33.79; H 1.20; $\mathrm{N}$ 4.55, S 3.47; found C 34.37; H 1.02; N 4.54, S 3.75.

\section{Conflict of Interests}

The authors declare that there is no conflict of interests.

\section{Acknowledgements}

The University of Rennes 1 is acknowledged for supporting the article processing charge. This project received funding from the European Union's Horizon 2020 research and innovation program (Marie Curie grant agreement $\mathrm{N}^{\circ}$ 800719). L. N. thanks Jeffrey R. Long for hosting her in his laboratory during this Marie Curie internship. We thank the Université de Rennes 1 and the CNRS. K.B. acknowledges the Institut Universitaire de France (IUF). B.L.G. and F.G. thank the French GENCI/IDRIS-CINES centers for high-performance computing resources. F.G. acknowledges Région Bretagne for a SAD Grant. D.J. is indebted to the CCIPL for generous allocation of $c p u$ time. C. A. G. thanks the United States National Science Foundation Graduate Research Fellowship Program for support and acknowledges NSF grant CHE-1800252 for funding.

\section{References}

[1] Braslavsky, S. E., Pure Appl. Chem. 2007, 79, 293-465.

[2] Irie, M.; Fukaminato, T.; Matsuda, K.; Kobatake, S., Chem. Rev. 2014, 114, 12174-12277.

[3] Nakatani, K.; Piard, J.; Yu, P.; Métivier, R., Introduction: Organic Photochromic Molecules. In: Tian, H.; Zhang, J. (eds.). Photochromic materials: preparation, properties and applications. Wiley-VCH: 2016, 1-45.

[4] Zhang, J. J.; Zou, Q.; Tian, H., Adv. Mater. 2013, 25, 378-399.

[5] Stoll, R. S.; Hecht, S., Angew. Chem. Int. Ed. 2010, 49, 5054-5075.

[6] Russew, M. M.; Hecht, S., Adv. Mater. 2010, 22, 3348-3360.

[7] Klajn, R., Chem. Soc. Rev. 2014, 43, 148-184.

[8] Estrader, M.; Salinas Uber, J.; Barrios, L. A.; Garcia, J.; Lloyd-Williams, P.; Roubeau, O.; Teat, S. J.; Aromí, G., Angew. Chem. Int. Ed. 2017, 56, 15622-15627.

[9] Wilson, D.; Branda, N. R., Photochromic Materials in Biochemistry. In: Tian, H.; Zhang, J. (eds.). Photochromic materials: preparation, properties and applications, Wiley-VCH: 2016, 361-391.

[10] Beharry, A. A.; Woolley, G. A., Chem. Soc. Rev. 2011, 40, 4422-4437.

[11] Andreasson, J.; Pischel, U., Chem. Soc. Rev. 2015, 44, 1053-1069. 
[12] Ishii, N.; Kato, T.; Abe, J., Sci. Rep. 2012, 2, 819.

[13] Kobayashi, Y.; Abe, J., Adv. Opt. Mater. 2016, 4, 1354-1357.

[14] Abaskharon, R. M.; Culik, R. M.; Woolley, G. A.; Gai, F., J. Phys. Chem. Lett. 2015, 6, 521-526.

[15] Velema, W. A.; Szymanski, W.; Feringa, B. L., J. Am. Chem. Soc. 2014, 136, 2178-2191.

[16] Abe, J., Fast Photochromism of Bridged Imidazole Dimers. In: Irie, M.; Yokoyama, Y.; Seki, T.(eds.). New Frontiers in Photochromism. Springer Japan: Tokyo, 2013, 161-181.

[17] Kortekaas, L.; Browne, W. R., Chem. Soc. Rev. 2019, 48, 3406-3424.

[18] Dong, M.; Babalhavaeji, A.; Collins, C. V.; Jarrah, K.; Sadovski, O.; Dai, Q.; Woolley, G. A., J. Am. Chem. Soc. 2017, 139, 13483-13486.

[19] Knie, C.; Utecht, M.; Zhao, F. L.; Kulla, H.; Kovalenko, S.; Brouwer, A. M.; Saalfrank, P.; Hecht, S.; Bleger, D., Chem. Eur. J. 2014, 20, 16492-16501.

[20] Samanta, S.; McCormick, T. M.; Schmidt, S. K.; Seferos, D. S.; Woolley, G. A., Chem. Commun. 2013, 49, 10314-10316.

[21] Simeth, N. A.; Crespi, S.; Fagnoni, M.; König, B., J. Am. Chem. Soc. 2018, 140, 2940-2946.

[22] Huang, C.-Y.; Bonasera, A.; Hristov, L.; Garmshausen, Y.; Schmidt, B. M.; Jacquemin, D.; Hecht, S., J. Am. Chem. Soc. 2017, 139, 15205-15211.

[23] Natali, M.; Giordani, S., Chem. Soc. Rev. 2012, 41, 4010-4029.

[24] Guerin, J.; Leaustic, A.; Delbaere, S.; Berthet, J.; Guillot, R.; Ruckebusch, C.; Métivier, R.; Nakatani, K.; Orio, M.; Sliwa, M.; Yu, P., Chem. Eur. J. 2014, 20, 12279-12288.

[25] He, J.; He, J.; Wang, T.; Zeng, H., J. Mater. Chem. C 2014, 2, 7531-7540.

[26] Daichi, K.; Kyohei, S.; Seiya, K., Bull. Chem. Soc. Jpn. 2011, 84, 141-147.

[27] He, J.; Wang, T.; Chen, S.; Zheng, R.; Chen, H.; Li, J.; Zeng, H., J. Photochem. Photobio. A. 2014, 277, 45-52.

[28] Walko, M.; Feringa, B. L., Chem. Commun. 2007, 1745-1747.

[29] Kitagawa, D.; Nakahama, T.; Nakai, Y.; Kobatake, S., J. Mater. Chem. C 2019, 7, 2865-2870.

[30] Milić, J. V.; Schaack, C.; Hellou, N.; Isenrich, F.; Gershoni-Poranne, R.; Neshchadin, D.; Egloff, S.; Trapp, N.; Ruhlmann, L.; Boudon, C.; Gescheidt, G.; Crassous, J.; Diederich, F., J. Phys. Chem. C 2018, 122, 19100-19109. 
[31] Gatteschi, D.; Sessoli, R.; Villain, J., Molecular Nanomagnets. Oxford University Press: Oxford, 2006.

[32] Ferrando-Soria, J.; Vallejo, J.; Castellano, M.; Martínez-Lillo, J.; Pardo, E.; Cano, J.; Castro, I.; Lloret, F.; Ruiz-García, R.; Julve, M., Coord. Chem. Rev. 2017, 339, 17-103.

[33] Liddle, S. T.; van Slageren, J., Chem. Soc. Rev. 2015, 44, 6655-6669.

[34] Rinehart, J. D.; Long, J. R., Chem. Sci. 2011, 2, 2078-2085.

[35] Feng, X. W.; Mathonière, C.; Jeon, I. R.; Rouzières, M.; Ozarowski, A.; Aubrey, M. L.; Gonzalez, M. I.; Clérac, R.; Long, J. R., J. Am. Chem. Soc. 2013, 135, 15880-15884.

[36] Pinkowicz, D.; Ren, M.; Zheng, L. M.; Sato, S.; Hasegawa, M.; Morimoto, M.; Irie, M.; Breedlove, B. K.; Cosquer, G.; Katoh, K.; Yamashita, M., Chem. Eur. J. 2014, 20, 12502-12513.

[37] Cosquer, G.; Breedlove, B. K.; Yamashita, M., Dalton Trans. 2015, 44, 2936-2942.

[38] Cosquer, G.; Kamila, M.; Li, Z.-Y.; Breedlove, B. K.; Yamashita, M., Inorganics 2018, 6, 9.

[39] Guo, F.-S.; Day, B. M.; Chen, Y.-C.; Tong, M.-L.; Mansikkamäki, A.; Layfield, R. A., Science 2018, $362,1400$.

[40] Hojorat, M.; Al Sabea, H.; Norel, L.; Bernot, K.; Roisnel, T.; Gendron, F.; Le Guennic, B.; Trzop, E.; Collet, E.; Long, J. R.; Rigaut, S., J. Am. Chem. Soc. 2019, 141, 20026-20030.

[41] Gavrel, G.; Yu, P.; Léaustic, A.; Guillot, R.; Métivier, R.; Nakatani, K., Chem. Commun. 2012, 48, 10111-10113.

[42] Ruiz-Martínez, A.; Casanova, D.; Alvarez, S., Chem. Eur. J. 2008, 14, 1291-1303.

[43] Irie, M.; Lifka, T.; Kobatake, S.; Kato, N., J. Am. Chem. Soc. 2000, 122, 4871-4876.

[44] Kawai, S.; Nakashima, T.; Atsumi, K.; Sakai, T.; Harigai, M.; Imamoto, Y.; Kamikubo, H.; Kataoka, M.; Kawai, T., Chem. Mater. 2007, 19, 3479-3483.

[45] Walton, I. M.; Cox, J. M.; Benson, C. A.; Patel, D. G.; Chen, Y.-S.; Benedict, J. B., New J. Chem. 2016, 40, 101-106.

[46] Nakagawa, T.; Hasegawa, Y.; Kawai, T., J. Phys. Chem. A 2008, 112, 5096-5103.

[47] Zhang, C.; Morinaka, K.; Kose, M.; Ubukata, T.; Yokoyama, Y., Beilstein Journal of Organic Chemistry 2019, 15, 2161-2169.

[48] Chen, K. J.; Laurent, A. D.; Jacquemin, D., J. Phys. Chem. C 2014, 118, 4334-4345.

[49] Chantzis, A.; Cerezo, J.; Perrier, A.; Santoro, F.; Jacquemin, D., J. Chem. Theory Comput. 2014, 10, 3944-3957. 
[50] da Cunha, T. T.; Jung, J.; Boulon, M. E.; Campo, G.; Pointillart, F.; Pereira, C. L. M.; Le Guennic, B.; Cador, O.; Bernot, K.; Pineider, F.; Golhen, S.; Ouahab, L., J. Am. Chem. Soc. 2013, 135, 1633216335.

[51] Cole, K. S.; Cole, R. H., J. Chem. Phys. 1941, 9, 341-351.

[52] Meng, Y.-S.; Jiang, S.-D.; Wang, B.-W.; Gao, S., Acc. Chem. Res. 2016, 49, 2381-2389.

[53] Selvanathan, P.; Dorcet, V.; Roisnel, T.; Bernot, K.; Huang, G.; Le Guennic, B.; Norel, L.; Rigaut, S., Dalton Trans. 2018, 47, 4139-4148.

[54] Bernot, K.; Bogani, L.; Caneschi, A.; Gatteschi, D.; Sessoli, R., J. Am. Chem. Soc. 2006, 128, 79477956.

Received: 30 April 2020

Accepted: 14 July 2020

Published online: 19 August 2020

ORCID ID for authors

Lucie Norel ORCID ID 0000-0001-6654-1211

Kevin Bernot ORCID ID 0000-0001-8337-6246

Frédéric Gendron ORCID ID 0000-0002-1896-3978

Boris Le Guennic ORCID ID 0000-0003-3013-0546

Colin A. Gould ORCID ID 0000-0001-9539-1582

Denis Jacquemin ORCID ID 0000-0002-4217-0708

Stephanie Delbaere: ORCID ID 0000-0001-6846-6614

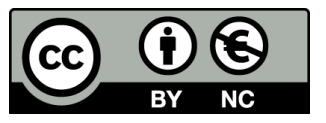

This article is licensed under a Creative Commons Attribution-NonCommercial 4.0 International License, which permits use, sharing, adaptation, distribution and reproduction in any medium or format, as long as it is non-commercial, you give appropriate credit to the original author(s) and the source, provide a link to the Creative Commons license, and indicate if changes were made. The images or other third-party material in this article are included in the article's Creative Commons license, unless indicated otherwise in a credit line to the material. If material is not included in the article's Creative Commons license and your intended use is not permitted by statutory regulation or exceeds the permitted use, you will need to obtain permission directly from the copyright holder. To view a copy of this license, visit http://creativecommons.org/licenses/by/4.0/. 